\title{
Uso popular de plantas medicinais por mulheres da comunidade quilombola de Furadinho em Vitória da Conquista, Bahia, Brasil
}

\section{Popularized use of medicinal plants by women of Quilombo of Furadinho community in Vitoria da Conquista, Bahia, Brazil}

\author{
Lázaro Ribeiro de Oliveira ${ }^{1}$
}

\begin{abstract}
Resumo: Objetivou-se com este trabalho realizar um levantamento do uso popular de plantas medicinais por mulheres da Comunidade Quilombola de Furadinho em Vitória da Conquista-Bahia. O trabalho foi realizado na comunidade Quilombola de Furadinho, visando identificar as principais plantas utilizadas com fins medicinais, as formas de obtenção, sua indicação medicinal, a parte da planta utilizada, as formas de preparo, bem como as formas de obtenção e transmissão deste conhecimento. Para a realização dessa pesquisa foram entrevistadas 14 mulheres com idades variadas, moradoras dessa comunidade, através de questionários semi estruturados, e análise descritiva. Constatou-se um vasto conhecimento relacionado ao uso de plantas medicinais entre as entrevistadas, o qual foi adquirido de forma oral através de pais e avós. As plantas medicinais utilizadas são em sua maioria cultivadas em quintais, sendo as folhas a parte mais utilizada nas preparações medicamentosas, e a principal forma de preparo são os chás. Foram identificadas 30 plantas com fins medicinais e terapêuticos, sendo a Erva cidreira, o Capim santo, o Hortelã grosso, a Arruda e a Erva doce as mais utilizadas.
\end{abstract}

Palavras-chaves: Conhecimento tradicional, Medicina popular, etnobotânica

\begin{abstract}
This work aimed to carry out a survey of the popular use of medicinal plants by women of Furadinho Quilombo Community in Vitória da Conquista, Bahia. The work was conducted in the Furadinho Quilombo Community, aiming at identifying the main plants used for medical purposes, the ways of obtaining, its indication medicinal, the part of the plant used, the forms of preparation, as well as ways of obtaining and transmission of this knowledge. For the realization of this research were interviewed 14 women with ages varied, dwell in this community, through semi-structured questionnaires, and descriptive analysis. It was found a vast knowledge related to the use of medicinal plants among the interviewees, which was purchased in oral form by parents and grandparents. Medicinal plants used are mostly grown in quintals, being the sheets the most used in medicinal preparations, and the main form of preparation are the teas. Were identified 30 plants with medicinal and therapeutic purposes, being the lemon grass, the Grass holy, the Mint grosso, Arruda and Erva Doce the most used.
\end{abstract}

Key words: Traditional Knowledge, popular Medicine, Ethnobotany

\footnotetext{
*Autor para correspondência

Recebido para publicação em 21/05/2015; aprovado em 15/07/2015

${ }^{1}$ Engenheiro Agrônomo, Especialista em Meio Ambiente e Desenvolvimento, UESB, Lro.agro@ yahoo.com.br.
} 


\section{INTRODUÇÃO}

Muitas comunidades tradicionais possuem um vasto conhecimento relacionado ao uso dos recursos vegetais encontrados nos ambientes onde as mesmas estão inseridas, sendo que esse conhecimento é adquirido empiricamente e transmitido de forma oral de geração em geração.

Apesar da popularização da medicina ocidental (alopática), muitas comunidades ainda continuam crendo e utilizando as plantas medicinais como um aliado contra as eventuais enfermidades, muitas vezes devido aos altos custos dos medicamentos alopáticos ou talvez movido pelo medo de que os medicamentos possam apresentar efeitos colaterais bem mais sérias (SALES et at., 2009).

MOREIRA et al. (2002) destaca que, considerando a ineficácia do sistema oficial de saúde pública e a condição econômica da maioria da população, não é tão surpreendente a sobrevivência do conhecimento tradicional sobre plantas medicinais, sendo que a transmissão oral desse conhecimento é muitas vezes a única maneira de registro desse saber.

De acordo com Mosca e Loiola (2009) no Nordeste do Brasil, apesar da grande influência dos meios de comunicação e do número crescente de farmácias na região, o uso de plantas medicinais ainda é frequente, tanto no meio rural e urbano, sendo comum principalmente neste último, a presença de raizeiros em pontos estratégicos de algumas cidades.

Levando-se em consideração a forte influência da herança cultural africana na medicina popular do Brasil e que os quilombolas carregam consigo e ainda praticam os costumes de seus antepassados, promover o resgate do conhecimento tradicional sobre plantas medicinais em Comunidades Quilombolas, apresenta-se como uma ferramenta para a promoção da valorização do saber tradicional que estas comunidades carregam. Além disso, fornecerá importantes informações que poderão contribuir no processo de desenvolvimento de programas e projetos de pesquisa de plantas medicinais.

Objetivou-se com este trabalho realizar um levantamento do uso popular de plantas medicinais por mulheres da Comunidade Quilombola de Furadinho em Vitória da Conquista-Bahia.

\section{MATERIAL E MÉTODOS}

\section{Caracterização da área de estudo}

O presente trabalho foi desenvolvido na comunidade Remanescente de Quilombo de Furadinho, localizado no município de Vitória da Conquista- Bahia.

A fitofisionomia do município é típica de área de transição entre a Mata Atlântica e a Caatinga, ocorrendo uma vegetação conhecida localmente como mata de cipó.

A comunidade de Furadinho foi reconhecida oficialmente em 2006 pela Fundação Palmares como um remanescente de Quilombo, estando localizada a $36 \mathrm{~km}$ da sede do município de Vitória da Conquista-Bahia e conta com aproximadamente 120 famílias residindo no local.

\section{Coleta de dados}

Inicialmente foi contatada uma liderança da comunidade, a qual forneceu informações relacionadas a comunidade e disponibilizou um morador para acompanhar o pesquisador durante as visitas.

Para o levantamento de dados foram realizadas duas visitas, durante o mês de novembro de 2014, onde entrevistou-se 14 mulheres com idades entre 38 e 87 anos, sendo que, duas delas, são consideradas como referência na utilização de plantas para fins medicinais na comunidade de Furadinho.

As demais entrevistas foram realizadas em residências selecionadas de forma aleatória, com base na disposição das moradoras em colaborar com a presente pesquisa.

Para as entrevistas foram utilizados questionários semiestruturados com 20 questões divididos em duas partes, a saber: a primeira a respeito da investigação sobre os dados sócio-demográficos dos participantes (sexo, origem, religião, idade, grau de escolaridade, ocupação, doenças mais comuns) além de questões relacionadas ao conhecimento e preservação das plantas medicinais; e a segunda, questões referentes ao conhecimento, preparação, indicação e administração de plantas medicinais.

As plantas citadas e encontradas na residência das entrevistadas ou em locais próximos, foram fotografadas, acondicionadas sob forma de exsicatas e identificadas através de consulta a material bibliográfico e ao herbário virtual Reflora.

Em seguida foi realizada a tabulação dos dados utilizando planilhas do sistema Microsoft Excel 2010, sendo posteriormente analisados tanto quantitativa como o qualitativamente.

\section{RESULTADOS E DISCUSSÃO}

As entrevistadas possuíam idade entre 38 a 87 anos, com média de 63 anos de idade. A maioria (71\%) nasceu e foi criada na localidade, professam a religião católica (93\%), sendo que todas declararam fazer uso de algum tipo de planta medicinal quando necessário.

Diversos estudos etnobotânicos de plantas medicinais têm demonstrado que pessoas idosas detêm um maior conhecimento sobre as plantas medicinais. Silva et al.(2007), em um levantamento etnobotânico e etnofarmacológico de plantas medicinais utilizadas por comunidades rurais de Mutuípe-Bahia, observaram que o conhecimento sobre as espécies medicinais está alicerçado nas pessoas mais idosas da comunidade, especialmente as mulheres, que são as detentoras do conhecimento. Oliveira (2012), num estudo na comunidade Bola Verde, Teofilândia, Bahia, observou que pessoas mais idosas, com idade acima de 50 anos, detinham maior conhecimento sobre as plantas medicinais.

É de se esperar que as pessoas mais idosas tenham maior conhecimento sobre plantas, seja pela própria experiência de vida, seja pelo fato de, frequentemente, serem mais acometidas por doenças.

$\mathrm{O}$ alto percentual de utilização de plantas medicinais verificado entre as entrevistadas, pois todas declararam fazer uso algum tipo de planta medicinal quando necessário, pode ser motivado devido ao escasso acesso a serviços de saúde na localidade, visto que, na localidade existe apenas um pequeno posto de saúde, onde uma vez por mês é realizado 
atendimento médico aos moradores.

Diante disso, a prática popular do uso de plantas medicinais acaba tornando-se uma alternativa viável para o tratamento de doenças ou para a manutenção da saúde dos moradores.

Trabalhos realizados em condições semelhantes também encontraram um alto percentual de uso de plantas medicinais entre os entrevistados. Feijó et. al. (2013) numa pesquisa realizada no bairro de Salobrinho em Ilhéus-Ba, constatou que $97 \%$ dos entrevistados afirmaram fazer uso habitual das plantas medicinais ou pelo menos já tê-las utilizado em algum momento da sua vida, o que pode estar associado talvez devido a um resquício dos costumes da vida no campo, origem da maior parte dos entrevistados, ou à presença de um único posto de saúde no bairro, que muitas vezes é insuficiente para o atendimento de toda a comunidade fazendo com que as pessoas procurem outras formas de terapia como as plantas medicinais.

Silva (2003) destaca que a população dessas comunidades utiliza plantas medicinais na cura das doenças, principalmente devido a aspectos culturais, religiosos, mas também pela dificuldade de usufruir da chamada medicina convencional, muitas vezes com preços elevados sendo impossível sua utilização por comunidades mais carentes. Além disso, existe a falta de medicamentos em locais de difícil acesso ou ainda por acreditar no potencial dos chamados produtos naturais, associados a propaganda de que faz bem .

Entre as entrevistadas há um baixo nível de escolaridade, pois apenas $8 \%$ concluiu o ensino médio. A maioria é analfabeta (43\%), $21 \%$ apenas lê ou escreve e $28 \%$ possui ensino fundamental incompleto.

Tuller (2011) destaca que, quanto ao grau de escolaridade, quanto menor mais intenso o uso de espécies medicinais, pois a falta de informação pode restringir o uso de outros tipos de tratamentos na cura das doenças.

Ao serem questionadas sobre qual familiar possui maior conhecimento relacionado ao uso de plantas medicinais, as entrevistadas declararam que elas mesmas possuem um maior conhecimento sobre a temática.

Diversos estudos tem demonstrado uma predominância de mulheres como detentoras do conhecimento popular relacionado a utilização de plantas medicinais, o qual segundo Viu et al. (2010), pode ser justificado ao se considerar que ao longo da história, nas várias sociedades, tem sido designada às mulheres a responsabilidade de tarefas domésticas e o cuidado das crianças, sendo as mesmas as principais responsáveis pelo tratamento caseiro das doenças mais simples através de plantas.

A predominância das mulheres como detentoras do conhecimento popular sobre plantas medicinais está relacionada também com a facilidade de obtenção das plantas medicinais, geralmente encontradas nos quintais e arredores das casas, sendo que quando as plantas a serem utilizadas são espécies encontradas na mata ou em locais distantes os homens da família são geralmente os escolhidos para sua coleta. Tal fato é confirmado ao contatar-se que todas das mulheres entrevistadas cultivam pelo menos um tipo de planta medicinal em seu quintal.

Relacionando a citação de cada planta a sua forma de obtenção, verificou-se que em 56\% dos casos a planta foi obtida através de cultivo próprio no quintal, $21 \%$ é obtido através de vizinhos, $20 \%$ é coletado em mata e 3\% é comprado em feiras livres (Figura 1).

Figura 1. Formas de obtenção de plantas medicinais por mulheres moradoras da comunidade quilombola de Furadinho em Vitória da Conquista-Bahia, 2015.

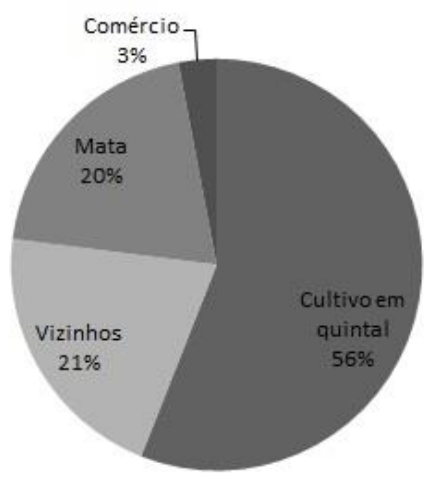

O hábito do cultivo de plantas medicinais observado na comunidade é uma prática de grande importância para a conservação das espécies vegetais, visto que, a retirada de espécies nativas de seu ambiente natural, pode ocasionar significativas reduções das populações destas espécies.

Em relação ao conhecimento tradicional sobre as plantas medicinais, todas as entrevistadas relataram que o conhecimento que elas utilizam aprenderam com seus pais e avós, sendo que duas delas, além dos pais e avós, citaram também a troca de informações com vizinhos.

Silva et. al.(2012) num estudo sobre plantas medicinais usadas pela comunidade do povoado de Laços (Tanhaçu/Bahia) observou que, 48,8\% dos entrevistados adquiriram conhecimento sobre o uso das plantas medicinais através dos pais, $24,8 \%$ dos avós e os demais entrevistados adquiriram dos amigos ou pessoas conhecidas (26,3\%), onde foi possível concluir que o conhecimento sobre o uso das plantas medicinais é repassado, na sua grande maioria, entre as gerações, permanecendo no seio familiar.

Resultado semelhante foi encontrado por Ferreira et al (2014) num levantamento etnobotânico de plantas medicinais na comunidade quilombola Carreiros, Mercês - Minas Gerais, onde os entrevistados relataram ter aprendido sobre as plantas medicinais, em geral com os familiares (pais e avós) e pessoas mais velhas da comunidade.

Diante desses dados é possível observar que todo o conhecimento sobre o uso de plantas medicinais nessas comunidades foi, e continua sendo transmitido oralmente, através de familiares às gerações posteriores, não havendo nenhum outro veículo citado pelas entrevistadas como meio de comunicação, médico, amigo etc.

Quanto a transmissão do conhecimento relacionado ao uso de plantas medicinais aos demais familiares, a maioria das informantes $(71,5 \%)$ declarou preocupação em transmitir estas informações aos mais jovens, sendo que, é realizada apenas de forma oral, ao se indicar ou receitar alguma planta medicinal para a cura de determinadas enfermidades que acometa algum familiar ou vizinho.

Dos $28,5 \%$ dos entrevistados que declararam não se preocupar em transmitir este conhecimento, justificaram um crescente desinteresse dos mais jovens em relação a 
utilização de plantas medicinais, provocado principalmente por uma inversão de valores, onde vêem o tradicional como arcaico, e também pelo acesso fácil aos medicamentos industrializados. Silva et. al. (2012) obtiveram resultado parecido ao apresentado neste trabalho, ao realizar um estudo em Tanhaçu/Bahia, onde observaram que, parte dos entrevistados que afirmaram utilizar plantas medicinais, $71,3 \%$ costuma indicar o seu uso, justificando que é necessário transmitir esse conhecimento, já que tem efeito comprovado na prática, vivenciada ao longo de diversas gerações. Contudo, 28,7\% dos entrevistados afirmaram não indicar o uso de plantas medicinais.

Foi observado um elevado percentual de migração entre os familiares das entrevistadas onde, em $71,5 \%$ das residências visitadas, pelo menos algum membro da família migrou para um centro urbano para trabalhar ou estudar, sendo que destes, 54\% migraram para a cidade de São Paulo, $31 \%$ para Vitória da Conquista e $15 \%$ para outros estados, objetivando trabalhar em atividades que proporcionassem uma melhor renda ou para estudar. Este resultado foi superior ao encontrado em estudos realizados por Pereira, et al.(2006), onde foi constatado que $31,8 \%$ das famílias de agricultores residentes no entorno de Vitória da Conquista tinha algum membro que migrou para grandes centros.

Esta alta porcentagem de migração é um aspecto negativo em relação a preservação do conhecimento tradicional, visto que, segundo Freitas (2012) o êxodo rural aliado ao desinteresse dos jovens por este conhecimento vem provocando perdas de informações importantes associadas aos recursos vegetais. Neste sentido, o resgate deste saber necessita de maior atenção, principalmente devido ao rápido processo de aculturação e à erosão genética advinda da forte atividade humana e uso insustentável dos recursos naturais.

De acordo com os dados obtidos, os sintomas e doenças mais frequentes entre os entrevistados e seus familiares são: pressão alta (20\%), seguido pelas doenças do aparelho respiratório como gripe e asma (17\%), dores diversas (16\%), diabetes $(13 \%)$, doenças oculares $(7 \%)$ e Febre $(7 \%)$ (Figura 2).

Figura 2. Doenças e sintomas mais frequentes entre as mulheres entrevistadas e seus familiares (\%) na comunidade de Furadinho em Vitória da Conquista-Bahia, 2015.

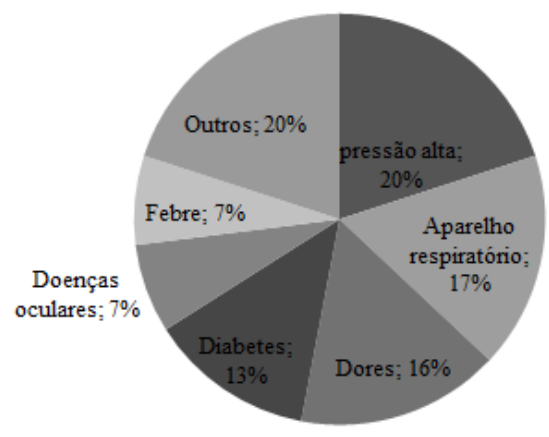

Bezerra et al. (2013) num estudo objetivando estimar a prevalência de hipertensão arterial em residentes das comunidades quilombolas de Vitoria da Conquista e avaliar possíveis fatores associados verificou entre esses residentes de comunidades quilombola, uma população étnico-racial com características de grande exclusão histórico-social, a prevalência de hipertensão foi considerada elevada, principalmente quando comparada com estudos realizados em populações com faixas etárias semelhantes.

Segundo este autor, as condições de vulnerabilidade das comunidades quilombolas estudadas foram observadas pelos baixos níveis de escolaridade e pela concentração em classes econômicas mais baixas, podendo estes fatores, parcialmente, justificarem a elevada prevalência de hipertensão arterial encontrada. O impacto nas condições de saúde de populações que se concentram em níveis socioeconômicos mais baixos é decorrente da falta de acesso ao sistema de saúde, grau de informação, compreensão do problema e adesão ao tratamento (BEZERRA et al.,2013).

Entre as indicações das plantas medicinais citadas destaca-se as plantas indicadas para doenças do aparelho respiratório (20\%), seguido por doenças do aparelho digestivo $(14,5 \%)$, dores diversas (12\%), calmante/insônia (11\%), febre $(9 \%)$, gases e prisão de ventre $(4 \%)$, pressão alta $(3,5 \%)$ e $10 \%$ são utilizadas em rituais como banhos de descarrego ou plantio em frente a residência para afastar mau olhado (Figura $3)$.

Figura 3. Indicações de plantas medicinais citadas por mulheres moradoras da comunidade quilombola de Furadinho em Vitória da Conquista-Bahia, 2015.

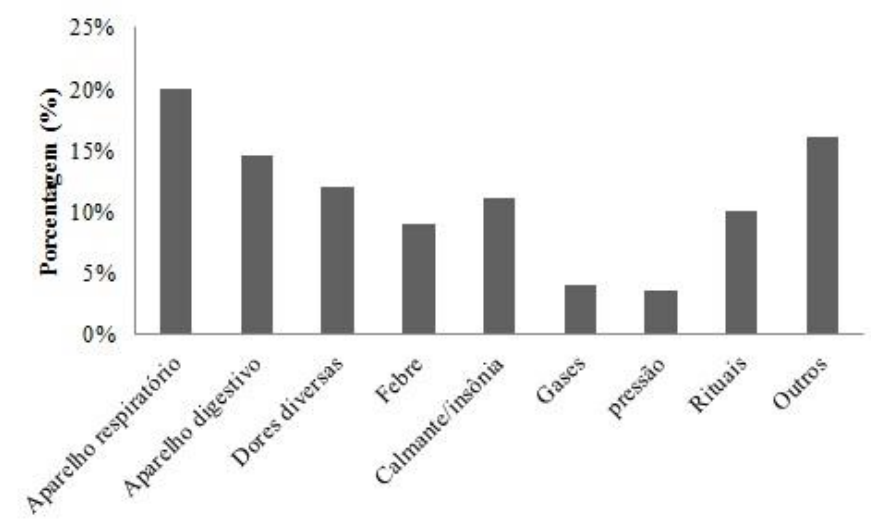

Apesar de ter sido constatado um elevado percentual de pessoas acometidas por pressão alta (20\%), verificou-se um baixo número de indicações de plantas medicinas para o tratamento desta doença $(3,5 \%)$. Provavelmente, por se tratar de doença crônica, as pessoas tendem a procurar atendimento médico convencional, aderindo ao tratamento medicamentoso.

Quanto a parte da planta utilizada, há uma predominância no uso das folhas (56\%), sendo que $4 \%$ das entrevistadas declararam utilizar as folhas juntamente com sementes, como é o caso da erva doce, por exemplo. Além disso, $3 \%$ das entrevistadas declararam utilizar as folhas juntamente com a flor. Em diversos estudos etnobotânicos realizados no Brasil, as folhas são frequentemente a parte mais utilizada (BORGES e BAUTISTA, 2010; SILVA et al., 2012; TULER 2011; SALES et al., 2009; FERREIRA et al., 2014; MOTA e DIAS, 2012).

De acordo com Tuler (2011), sob a ótica da conservação dos recursos naturais, a utilização majoritária das folhas nas preparações medicinais é positiva, pois não causa a morte do espécime coletado, contribuindo para a preservação da flora 
local. Entretanto, é necessário alertar e orientar a comunidade sobre a necessidade de incentivar o plantio de novos indivíduos das espécies mais importantes e que, por consequência, sofrem maior pressão antrópica. Outras partes empregadas são: planta inteira (5\%), casca (14\%), ramo (9\%), semente $(6 \%)$, raiz $(2 \%)$, tubérculo (1\%) (Figura 4$)$.

Figura 4. Partes utilizadas nas preparações medicamentosas na comunidade de Furadinho em Vitória da Conquista-Bahia, 2015.

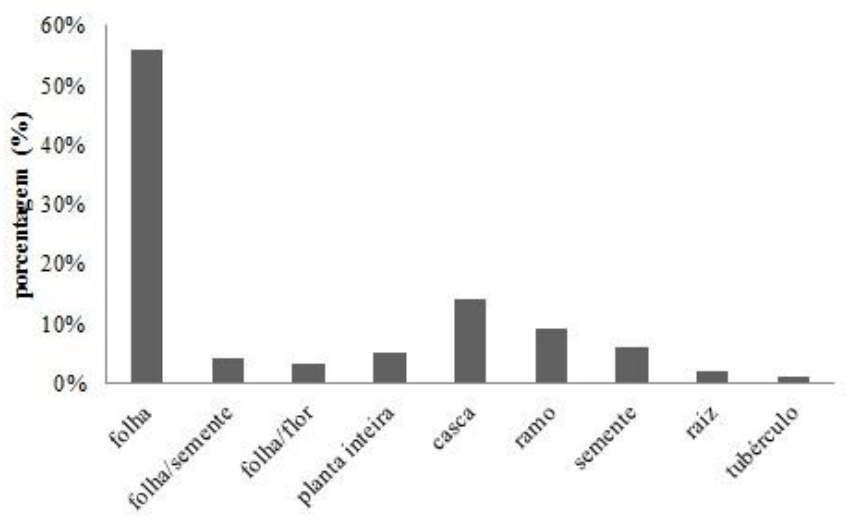

A utilização da casca foi bastante citada, principalmente de espécies arbóreas, como o mulungu, a catinga de porco, a jurema preta e a madeira nova. Silva et al. (2012) alertam que o uso de raízes e cascas é um aspecto que merece atenção, tendo em vista que a extração dessas estruturas vegetativas pode causar a morte da planta.

No que diz respeito as formas de uso, conhecer as formas em que as plantas são utilizadas é de grande importância em pesquisas etnobotânicas, pois permite entender qual o órgão ou parte utilizada para determinada afecção.

A principal forma de preparo utilizada são os chás (60\%), sendo que diversos estudos tem apontado o chá com principal forma de uso de plantas medicinais (BORGES e BAUTISTA, 2010; SALES et al., 2009; MOTA e DIAS 2012;FERREIA et al., 2014; SOARES et al., 2009). Em seguida tem-se o banho (16\%), o xarope (7\%) e o sumo, gargarejo, suco e deixado de molho em água com $3 \%$ cada (Figura 5). Os banhos destacam-se pois, além de serem utilizados como forma de tratamento externo para diversos sintomas e doenças, como o sarampo e febre, possui uma simbologia devido a sua virtude purificadora e transformadora, influenciada, provavelmente, pela ancestralidade africana (ALMEIDA, 2013).

Figura 5. Formas de uso das plantas medicinais pelas mulheres moradoras da comunidade quilombola de Furadinho em Vitória da Conquista-Bahia, 2015.

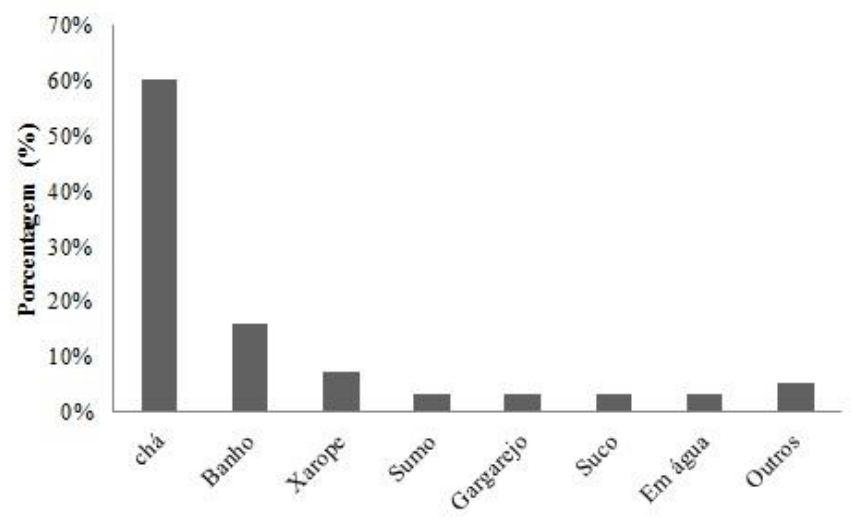

Foram mencionadas 47 plantas utilizadas com fins medicinais e terapêuticos sendo que, destas, 30 foram identificada (Tabela 1).

Entre as plantas citadas, a erva cidreira destacou-se como a planta com maior número de citações, em seguida o capim santo e o hortelã grosso, a arruda e a erva doce.

Ao fazer um estudo do uso de plantas medicinais pela comunidade quilombola Senhor do Bonfim - Areia-PB, Sales et al., (2009) obtiveram resultado semelhante ao observar que a erva cidreira e o capim santo foram as plantas mais citadas pelos moradores desta comunidade, seguido pela hortelã da folha miúda e pela a hortelã da folha graúda.

Tabela 1. Plantas identificadas, formas de uso, partes utilizadas e indicação pelas mulheres moradoras da comunidade quilombola de Furadinho em Vitória da Conquista-Bahia, 2015

\begin{tabular}{|c|c|c|c|c|c|}
\hline Família & $\begin{array}{l}\text { Nome comum/ } \\
\text { Científico }\end{array}$ & $\mathrm{Nc}^{*}$ & $\begin{array}{l}\text { Forma } \\
\text { de uso }\end{array}$ & $\begin{array}{c}\text { Parte } \\
\text { utilizada }\end{array}$ & Indicação \\
\hline Amaranthaceae & $\begin{array}{l}\text { Mastruz/Chenopodium ambrosioides L. } \\
\text { (Marisco e Spósito,2013). }\end{array}$ & 2 & Suco & Folhas & Verme, machucado \\
\hline Anacardiaceae & $\begin{array}{l}\text { Seriguela/Spondias purpurea L. (Reflora, } \\
\text { 2015). }\end{array}$ & 3 & $\begin{array}{l}\text { Chá } \\
\text { Banho }\end{array}$ & $\begin{array}{l}\text { Folhas } \\
\text { Folhas }\end{array}$ & $\begin{array}{l}\text { Pressão, gripe } \\
\text { Gripe }\end{array}$ \\
\hline Apiaceae & $\begin{array}{l}\text { Erva doce/Foeniculum vulgare Miller. } \\
\text { (Baracuhy et at.,2014). }\end{array}$ & 5 & Chá & $\begin{array}{l}\text { Ramo/folhas/ } \\
\text { semente }\end{array}$ & $\begin{array}{l}\text { Calmante, gases, } \\
\text { dores }\end{array}$ \\
\hline Asparagaceae & $\begin{array}{l}\text { Espada de São Jorge/Sansevieria } \\
\text { trifasciata Prain (Reflora, 2015). }\end{array}$ & 1 & Banho & Folhas & Descarrego \\
\hline Asteraceae & $\begin{array}{l}\text { Carqueja/Baccharis trimera (Less.) DC. } \\
\text { (Marisco e Spósito,2013). }\end{array}$ & 1 & Em água & Ramo & Diabetes \\
\hline Caprifoliaceae & $\begin{array}{l}\text { Sabugueiro/ Sambucus australis Cham. \& } \\
\text { Schltdl. (Baracuhy et al.,2014). }\end{array}$ & 3 & $\begin{array}{l}\text { Chá } \\
\text { Banho }\end{array}$ & $\begin{array}{l}\text { Folha, flor } \\
\text { Folha, flor }\end{array}$ & $\begin{array}{l}\text { febre, gripe } \\
\text { Sarampo }\end{array}$ \\
\hline Caric & Mamão/Carica papaya L. (Reflora, 2015) & 1 & Chá & Olho da folha & Estomago \\
\hline Fabaceae & $\begin{array}{l}\text { Mulungu/Erythrina velutina Willd. } \\
\text { (Baracuhy et al.,2014). } \\
\text { Pata de vaca/Bauhinia forficata Link. }\end{array}$ & 3 & $\begin{array}{l}\text { Gargarejo } \\
\text { Banho } \\
\text { Chá }\end{array}$ & $\begin{array}{l}\text { Casca do caule } \\
\text { Casca } \\
\text { Folhas }\end{array}$ & $\begin{array}{l}\text { Dor de dente } \\
\text { Males diversos } \\
\text { Diabetes }\end{array}$ \\
\hline
\end{tabular}




\begin{tabular}{|c|c|c|c|c|c|}
\hline & Marisco e Spósito, 2013). & & & & \\
\hline & $\begin{array}{l}\text { Barbatimão/Stryphnodendron adstrigens } \\
\text { (Mart.) Couille (Marisco e Spósito, 2013). }\end{array}$ & 1 & Banho & Casca & Cicatrizante \\
\hline & $\begin{array}{l}\text { Umburana/Amburana cearenses (Allemão) } \\
\text { A. C. Sm. (Marisco e Spósito, 2013). }\end{array}$ & 4 & Chá & Semente, casca & $\begin{array}{l}\text { Dores, estomago, } \\
\text { derrame }\end{array}$ \\
\hline Lamiaceae & $\begin{array}{ll}\text { Alecrim/Rosmarinus } & \text { officinalis } \\
\text { (Baracuhy et al.,2014). } & \end{array}$ & 4 & $\begin{array}{l}\text { Chá } \\
\text { Banho }\end{array}$ & $\begin{array}{l}\text { Folhas/ramo } \\
\text { Ramo }\end{array}$ & $\begin{array}{l}\text { Dor no corpo/ } \\
\text { mente }\end{array}$ \\
\hline & & & & & $\begin{array}{l}\text { Desconforto, dor } \\
\text { no corpo }\end{array}$ \\
\hline & Hortelã miúdo/Mentha $x \quad$ villosa & 4 & Chá & Folhas & Gripe, gases \\
\hline & $\begin{array}{l}\text { Huds.(Baracuhy et al.,2014). } \\
\text { Hortelã grosso/ Plectranthus amboinicus } \\
\text { (Lour.) Spreng (Baracuhy et al.,2014). }\end{array}$ & 6 & $\begin{array}{l}\text { Xarope/ } \\
\text { Chá }\end{array}$ & Folhas & $\begin{array}{c}\text { Problemas } \\
\text { respiratórios, } \\
\text { gases, ,inflamação, } \\
\text { estômago }\end{array}$ \\
\hline & $\begin{array}{l}\text { Boldo/Plectranthus } \quad \text { barbatus } \\
\text { (Reflora, 2015). }\end{array}$ & 2 & Chá & Folhas & Estômago \\
\hline $\begin{array}{l}\text { Leguminosae- } \\
\text { caesalpinoideae }\end{array}$ & Madeira nova/Pterogyne nitens Tull & 1 & Banho & Casca do caule & Olho ruim \\
\hline & & & & & sangue \\
\hline & $\begin{array}{l}\text { Pau ferro/Caesalpinia férrea (Lorenzi, } \\
\text { 1998). }\end{array}$ & 2 & $\begin{array}{l}\text { Xarope, de } \\
\text { molho em } \\
\text { água }\end{array}$ & $\begin{array}{l}\text { Casca do } \\
\text { caule, } \\
\text { semente. }\end{array}$ & Gripe,rins \\
\hline Liliaceae & $\begin{array}{l}\text { Babosa/Aloe vera (L.) Burm. F. (Baracuhy } \\
\text { et al., 2014). }\end{array}$ & 3 & Xarope & Folha & $\begin{array}{l}\text { Estômago, câncer, } \\
\text { cicatrizante }\end{array}$ \\
\hline Lythraceae & $\begin{array}{l}\text { Romã/Punica granatum L. (Marisco e } \\
\text { Spósito, 2013). }\end{array}$ & 2 & $\begin{array}{l}\text { Chá/ } \\
\text { gargarejo }\end{array}$ & Casca do fruto & Garganta \\
\hline Mimosaceae & $\begin{array}{l}\text { Barbatimão/Stryphnodendron adstringens } \\
\text { (Mart.) Coville. (Baracuhy et al., 2014). }\end{array}$ & 1 & Banho & Casca & Cicatrizante \\
\hline & Jurema preta / Mimosa tenuiflora (Willd.) & 2 & Chá & Casca do caule & Cicatrizante \\
\hline & Poiret. (Baracuhy et al.,2014). & & Banho & Casca do caule & $\begin{array}{l}\text { Olho ruim, atraso, } \\
\text { desfazer bruxaria. }\end{array}$ \\
\hline Myrtaceae & $\begin{array}{l}\text { Pitanga/Eugenia uniflora L. (Marisco e } \\
\text { Spósito, 2013). }\end{array}$ & 4 & $\begin{array}{l}\text { Chá } \\
\text { Banho }\end{array}$ & $\begin{array}{l}\text { Folhas } \\
\text { Folha }\end{array}$ & $\begin{array}{l}\text { Febre, gripe } \\
\text { Olho ruim }\end{array}$ \\
\hline Myristicaceae & $\begin{array}{l}\text { Noz moscada/Myristica fragrans Houtt } \\
\text { (Marisco e Spósito,2013). }\end{array}$ & 2 & $\begin{array}{l}\text { Chá, } \\
\text { ralado }\end{array}$ & Semente & Dor, pressão \\
\hline Passifloraceae & $\begin{array}{l}\text { Maracujá/Passiflora edulis Sims (Marisco } \\
\text { e Spósito,2013). }\end{array}$ & 2 & Chá & Folhas, casca & Calmante \\
\hline Phytolaccaceae & Guiné/Petiveria alliacea L.(Reflora, 2015). & 2 & banho & Pé inteiro & $\begin{array}{l}\text { Descarrego, dor no } \\
\text { corpo }\end{array}$ \\
\hline Plantaginaceae & $\begin{array}{l}\text { Trançagem /Plantago major L. } \\
\text { (Marisco e Spósito, 2013). }\end{array}$ & 1 & Suco & Folhas & Inflamação \\
\hline Poaceae & $\begin{array}{l}\text { Capim da lapa/Cymbopogon citratus Stapf. } \\
\text { (Baracuhy et al.,2014). }\end{array}$ & 6 & Chá & Folhas & $\begin{array}{l}\text { Calmante, febre, } \\
\text { gripe, } \\
\text { Tosse }\end{array}$ \\
\hline Punicaceae & $\begin{array}{l}\text { Romã/Punica granatum L. (Baracuhy et } \\
\text { al.,2014). }\end{array}$ & 2 & $\begin{array}{l}\text { Chá/ } \\
\text { Gargarejo }\end{array}$ & Casca do fruto & Garganta \\
\hline Rutaceae & $\begin{array}{l}\text { Arruda/Ruta graveolens L. (Baracuhy et } \\
\text { al.,2014). }\end{array}$ & 5 & Chá, sumo & Folhas, ramo & Dor, febre \\
\hline Verbanaceae & $\begin{array}{l}\text { Erva cidreira/Lippia alba (Mill) N.E. Br. } \\
\text { (Baracuhy et al.,2014). }\end{array}$ & 10 & $\begin{array}{l}\text { Cultivada } \\
\text { Chá }\end{array}$ & $\begin{array}{l}\text { Planta inteira } \\
\text { Ramo/folhas }\end{array}$ & $\begin{array}{l}\text { Mal olhado } \\
\text { Calmante, } \\
\text { digestão, gripe, } \\
\text { dores, pressão. }\end{array}$ \\
\hline
\end{tabular}

\section{CONCLUSÕES}

Foi verificado um vasto conhecimento relacionado ao uso de plantas medicinais entre as mulheres entrevistadas, sendo que este por sua vez foi adquirido de forma oral através de pais e avós.

As plantas medicinais utilizadas são em sua maioria cultivadas em quintais, sendo as folhas a parte mais utilizada nas preparações medicamentosas, e a principal forma de preparo são os chás.

Foram identificadas 30 plantas com fins medicinais e terapêuticos, sendo a Erva cidreira, o Capim santo, o Hortelã grosso, a Arruda e a Erva doce as mais utilizadas. 


\section{REFERÊNCIAS BIBLIOGRÁFICAS}

ALMEIDA, M. Z. de.Plantas Medicinais.Salvador-BA :EDUFBA, 2011.Bahia, Brasil: hipertensão arterial e fatores associados. Cad. Saúde Pública, Rio de Janeiro, 29(9):1889-1902, 2013.

BARACUHY, J. G. de V.; FURTADO, D. A.; FRANCISCO, P. R. M.; LIMA, J. L. S. de; PEREIRA, J. P. G.. Plantas Medicinais de Uso comum no Nordeste do Brasil. Campina Grande-PB : EDUFCG, 2014.

BEZERRA, V. M.; ANDRADE, A. C. de S.; CESAR, C. C.; CAIAFFA, W. T.Comunidades quilombolas de Vitória da Conquista, Bahia, Brasil: hipertensão arterial e fatores associados. Cad. Saúde Pública, Rio de Janeiro, p. 1889-1902, 2013.

BORGES, N. K.; BAUTISTA, H. P. Etnobotânica de Plantas Medicinais na Comunidade de Cordoaria, Litoral Norte do Estado da Bahia, Brasil. Plurais,Salvador,V.1,n. 2,p. 153-174,mai-ago, 2010.

FEIJÓ, E.V. R. S.; PEREIRA, A. S.; SOUZA, L. R.; SILVA, L. A. M.; COSTA, L. C. B. Levantamento preliminar sobre plantas medicinais utilizadas no bairro Salobrinho no município de Ilhéus, Bahia. Revista Brasileira de Plantas Medicinais, Campinas, v.15, n.4, p.595-604, 2013.

FERREIRA, F. M. C.; LOURENÇO, F. J. de C.; BALIZA ,D. P. Levantamento etnobotânico de plantas medicinais na comunidade quilombola Carreiros, Mercês - Minas Gerais. Revista Verde de Agroecologia e Desenvolvimento Sustentável, Pombal - PB, v 9, n. 3 , p. 205- 212, , 2014.

FREITAS, A. V. L.. Plantas medicinais: um estudo etnobotânico nos quintais do Sítio Cruz, São Miguel, Rio Grande do Norte, Brasil. Revista Brasileira de Biociências, Porto Alegre, v. 10, n. 1, p. 48-59, 2012.

LORENZI, H. Manual de identificação e cultivo de plantas arbóreas nativas do Brasil. Nova odessa- SP: Editora Plantarum, 1998.

MOTA, R. dos S. ; DIAS, H. M.. Quilombolas e recursos florestais medicinais no sul da Bahia, Brasil. Interações, Campo Grande, v. 13, n. 2, p. 151-159, 2012.

MOREIRA, R. de C. T.; COSTA, L. C. do B.; COSTA, R. C. S.; ROCHA, E A.. Abordagem Etnobotânica acerca do Uso de Plantas Medicinais na Vila Cachoeira, Ilhéus, Bahia, Brasil. Acta Farm. Bonaerense, 2002.

MARISCO, G.; SPÓSITO, R. A.. Plantas medicinais utilizadas pela comunidade de São Sebastião Vitória da Conquista-Ba. Edições UESB, Vitória da ConquistaBA, 2013.
MOSCA, V. P.; LOIOLA, M. I. B..Uso popular de plantas medicinais no Rio Grande do Norte, Nordeste do Brasil. Revista Caatinga, vol. 22, núm. 4, pp. 225-234, 2009.

PEREIRA, M. P.; MENEZES, A. M. S. de; FARIAS, D. da H.; BONFIM, J. A.; ABREU, R. W. M. de; JÚNIOR, V. $C$..Perfil da agricultura realizada no entorno da sede do município de Vitória da Conquista- BA. 58 Reunião Anual da SBPC. Florianópolis, SC, 2006.

Reflora - Herbário Virtual. Disponível em: < http:// reflora.jbrj.gov.br/jabot/herbarioVirtual/>.Acesso em: 10 out. 2015 .

SALES, G.P. dos S.; ALBUQUERQUE, H. N. de; CAVALCANTI, M. L. F..Estudo do uso de plantas medicinais pela comunidade quilombola Senhor do Bonfim - Areia-PB. Revista de biologia e ciências da terra. 2009.

SILVA, M. P. L. da; JUNIOR, A. A. A.; SILVA, da F.; SILVA; da M..Levantamento etnobotânico e etnofarmacológico de plantas medicinais utilizadas por comunidades rurais de Mutuípe-Ba integrantes do "projeto ervas". Cruz das Almas - BA, 2007.

SILVA, N, C, B.. Bioprospecção de plantas medicinais com potencial biotecnológico: estudo etnofarmacológico de três comunidades tradicionais da região da Chapada Diamantina, BA. UFRJ, 2003.

SILVA, N. C. B.; REGIS, A. C.D.;ALMEIDA, M. Z. Estudo Etnobotânico em Comunidades Remanescentes de Quilombo em Rio de Contas - Chapada Diamantina Bahia. Revista fitos, vol.7, $\mathrm{n}^{\circ} 2,2012$.

SILVA, S. L.da C.;GUALBERTO, S. A.; MACEDO, G. E. L.;SILVEIRA, T. C. da;SILVA, D. C. da. Plantas medicinais usadas pela comunidade do povoado de laços (Tanhaçu/Bahia) e encontradas na floresta nacional Contendas do Sincorá. Revista Caatinga, Mossoró, v. 25, n. 3, p. 130-136, 2012.

SOARES, M. A. A.; BRAGA, J. R. P.; MOURÃO, A. E. B.; PARENTE, K. M. da S.; FILHO, E. G. Levantamento etnobotânico das plantas medicinais utilizadas pela população do município de Gurinhém - Paraíba. Revista Homem, Espaço e Tempo, 2009.

TULER, A. C. Levantamento etnobotânico na comunidade rural de São José da Figueira, Durandé, MG, Brasil. Alegre: UFES. Trabalho de Conclusão de Curso apresentado ao Centro de Ciências Agrárias, Universidade Federal do Espírito Santo, 2011.

VIU, A, F. .M.; VIU, M.A.O.; CAMPOS, L.Z.O. Etnobotânica: uma questão de gênero? Revista Brasileira de Agroecologia, v.5, n.1, p.138-147, Porto Alegre, 2010. 